\title{
LIFE ROLE SALIENCE AND SUBJECTIVE WELL-BEING AMONG MACEDONIAN EMPLOYEES: DOES FAMILY-SUPPORTIVE ORGANIZATION PERCEPTION MODERATE THIS RELATIONSHIP
}

\author{
BILJANA BLAŽEVSKA STOILKOVSKA ${ }^{1}$, ORHIDEJA ŠURBANOVSKA ${ }^{1}$, ANA FRITZHAND ${ }^{1}$, \\ and TATJANA STOJANOSKA IVANOVA ${ }^{2}$
}

\author{
Ss. Cyril and Methodius University, Skopje, Macedonia \\ Faculty of Philosophy \\ ${ }^{1}$ Department of Psychology \\ ${ }^{2}$ Department of Sociology
}

\begin{abstract}
Objectives: As many studies have shown, one of the most important tendencies of employees nowadays is to achieve worklife balance. Organizations should develop various activities and create supportive climate, within the framework of which employees will have opportunities to realize aforementioned goals which in turn would increase work productivity and work motivation. The aim of this paper was to examine how subjective well-being (life satisfaction and exhaustion) is associated with commitment to work and family roles under the conditions of strongly and weakly perceived organizational support for family life among health care professionals, teachers and bankers in Macedonia. Marriage duration and the number of children were introduced as control variables. Material and Methods: This cross-sectional study was conducted on a sample of 198 full-time employed doctors, nurses, teachers and bankers. Research variables were assessed using self-reported measures/questionnaires. Hierarchical multiple linear regression was performed for data analysis. Results: It was revealed that occupational role commitment contributed to highly expressed life satisfaction, while exhaustion was predicted by marital role commitment. These relationships were stronger among surveyed employees who reported positive family-supportive organization perception, but tested moderation effect of this variable was not statistically significant. Findings demonstrated that family-supportive organization perception moderated association of the number of children with life satisfaction, that is, participants who perceived an organization as family-supportive and had more children were more satisfied with their life in general. Conclusions: Results highlighted the importance of organizational orientation toward employees, their commitment to work and family roles, and their subjective well-being, as characteristics that might contribute to higher work engagement, success and family satisfaction. Int J Occup Med Environ Health 2018;31(3):281-291
\end{abstract}

Key words:

Life satisfaction, Exhaustion, Occupational, Parental and marital role commitment,

Family-supportive organization perception, Moderation effect

Received: April 6, 2017. Accepted: August 24, 2017.

Corresponding author: B. Blaževska Stoilkovska, Ss. Cyril and Methodius University, Faculty of Philosophy, Department of Psychology, Blvd. Goce Delčev 9A, 1000 Skopje, Macedonia (e-mail: biljanab@fzf.ukim.edu.mk). 


\section{INTRODUCTION}

Nowadays, both women and men are involved in many life roles such as parental, marital, occupational, etc. They need to be responsive for various activities in order to fulfill responsibilities linked to life roles. Therefore, one of the most important tendencies of employees in the last decade is to achieve work-family balance. Balancing between family responsibilities and work obligations may be evidently demanding, which may further lead to strain and poor subjective well-being. Greenhaus and Beutell [1] have stated that one of the major causes of work/family stressors are related to insufficient time to successfully perform in both domains. Therefore, work-family balance is achieved to the extent to which an individual is equally engaged in work and family role and is equally satisfied with both [2].

In that context, support from family members, particularly from marital partner, is extremely significant [3], but organizational support is highly important, as well. Organizations should develop various activities and create supportive climate, within the framework of which employees will have opportunities to navigate work and family roles [4] and to realize aforementioned goals which in turn could increase work productivity, work motivation and occupational health. Besides formal family-oriented practices and policies, informal organizational support, such as familysupportive organization perceptions, work-family culture, and work-family climate, is equally and even more important [5]. Lesser work-family conflict and greater well-being among employees are among positive outcomes of these informal types of organizational support [5].

One of the most challenging professions is teaching. It is expected from teachers to be committed to their work, which means daily contacts with students who range greatly in age, transferring knowledge and values to them, applying new teaching methods and to be oriented to continuous professional development. Health care professionals are also expected to be committed to their work, to help their patients and to deliver high quality health care. On the other hand, both groups are burdened with too much administrative work obligations and are faced with relatively poor working conditions. Bankers represent the professional group which realize daily contacts with existing clients, work with their finance and try to attract new clients.

Given that family-supportive organizational perception is relevant for work and family role participation and commitment, on the one hand, and subjective well-being, on the other hand, exploration of the mutual relations of these constructs among the aforementioned professions would represent important contribution to the current state in the field of career and family research as well as in the domain of human resources management practices.

\section{Life role salience}

Life role salience refers to the importance of each role to an individual's life [6]. According to Neville and Super [6], life role salience has 3 aspects. Commitment is attitudinal or affective component indicating the emotional attachment to a role and to the thing that one is expecting to do in that role (work, home, leisure). The second component, participation, is behavioral aspect of the life role salience and it denotes time and energy spent in the role. Knowledge, the third component, is cognitive in its nature and it can be acquired by experience [6]

Existing literature shows that commitment is the central element of role salience [7]. Life role salience can also be observed as an aspect of work and family role expectations. Namely, life role expectations represent internalized beliefs and attitudes regarding the personal importance of a role, about the standards for performance of the role, and about the manner in which personal resources such as time, money and energy should be committed to performance of the role [8]. The authors have developed the instrument intended to measure either the level of importance or value prescribed to involvement in a given role 
or the level of commitment of personal time and energy resources to performance of a given role [8].

Studying role commitment is relevant for explaining role stress that may arise due to the person's engagement in multiple life roles. It has been reported that this is especially true when engagement requires substantial time. Similarly, Perrone and Civiletto [9] found that only role commitment as one of the 3 aspects of role salience was a significant contributor to role strain, explaining that probably participation in a role or value expectations about a role did not necessarily lead to role strain, but it was psychological commitment to the role that related to role strain. In addition, they reported that role strain affected life satisfaction indirectly through coping efficacy [9]. Greenhaus and Powell [10] stated that in many studies positive relationship between role salience and work-family conflict was reported.

On the other hand, enrichment theory [5] presumes that multiple life roles have more positive than negative outcomes for individuals and their quality of life. Feeling of realization of own potential and compensation of sense of failure in one domain with experienced success in another area are among the benefits that come up when performing various roles are [11].

Both types of conclusions reveal that exploring relationship between multiple role salience and well-being, in particular among working parents, should be an important concern for career and family researchers.

\section{Family-supportive organizational perception}

Family-supportive organization perceptions (FSOP) are global perceptions employees form about how supportive their organization is regarding their families and family responsibilities [12]. Employees' perceptions that an organization where they work provides support for their family roles may be manifested by many practices such as providing time off to attend to family, allowing employees to talk about or deal with personal matters at work, and giving employees the opportunity to perform well in both family and work roles [13].

Previous studies have shown that FSOP is a significant predictor of job satisfaction, organizational commitment, and turnover intentions, above and beyond familyfriendly benefit availability and supervisor support [14]. Wayne et al.'s [13] study findings have revealed that FSOP is associated with less work-to-family conflict, which in turn relates to more positive partner attitudes toward the employee's work schedule.

Moreover, perceived organizational support may operate as a barrier against burnout and may foster recovery from work [15]. Namely, perceived support from work environment mitigates negative effect of work stress on subjective well-being and work-family conflict [16-18] and leads to higher job satisfaction and life satisfaction [19]. Kossek et al. [20], on the basis of the conducted extensive meta-analysis, have concluded that perceived general work support is related to family and job satisfaction and that perceived work and family support play central role in work-family conflict experiences among employees. In that line, as it has been cited by Ho et al. [21], familysupportive organizational perception is positively related to time spent with children and performing home activities, quality of interaction with family members and family satisfaction.

\section{Life satisfaction and exhaustion}

Life satisfaction is a cognitive component of subjective well-being [22]. It refers to an assessment process in which individuals evaluate their life quality according to their own criteria [23]. Consequently, the individual reports high life satisfaction to the degree that life conditions are congruent to these implicit standards [24]. Thus, as Pavot and Diener [24] have concluded, life satisfaction is a conscious cognitive estimation of one's life in which the estimation criteria depend on the person. In other words, how satisfied people are with their life situation is based 
on a comparison with a subjective norm, not a norm which is externally imposed [25].

While life satisfaction denotes global feeling of pleasure, happiness and realization in life in general [10], exhaustion is the main component of burnout describing person's feelings of being emotionally overextended by his/ her work [26]. Its expressions are physical fatigue and feeling of being emotionally and psychologically drained. Specifically, exhaustion is defined as a consequence of intensive physical, affective and cognitive strain or longterm consequence of prolonged exposure to certain job demands [27].

\section{Aim of the study}

Considering what has been mentioned above, the aim of this study was to examine how subjective well-being for health care professionals (doctors and nurses), primary and secondary school teachers and bankers is associated with their commitment to work and family roles under the conditions of strongly and weakly perceived organizational family-supportiveness. Precisely, it was assumed that family-supportive organization perceptions would have moderation effect on the relationship of life role salience (occupational, parental and marital) to life satisfaction and exhaustion.

In that way, this research has indented to contribute to the enlargement of the existing empirical evidence on the association of these relevant concepts in the field of work-life balance and work-life interface.

\section{MATERIAL AND METHODS}

\section{Sample and procedure}

This cross-sectional study was conducted on a sample of 198 employees (87 health care professionals, 85 teachers in primary and secondary schools and 26 bankers). All of them leave and work in Skopje, the capital of the Republic of Macedonia. Out of them, 160 were female, while 38 were male with mean age of 44.49 years old (standard deviation $(\mathrm{SD})=10.38$ ). In regard to their marital status, 169 study participants reported they were married, 6 stated they had been divorced and 22 answered they were in a long romantic relationship. Average duration of the respondents' marriage was 17.81 years $(\mathrm{SD}=10.92)$. Considering the number of children, 128 participants had 2 or 3 children, 44 respondents had one child and 25 of them did not have children.

The data was collected in the period of March-April 2016. Participants were informed that their contribution in the study was voluntary and anonymous, that the data would stay confidential and would only be used for research purposes.

\section{Measures}

The Abbreviated Family-Supportive Organization Perception Measure [28] - an instrument with 6 statements representing the philosophy or beliefs of the organization about family-supportiveness was used for measuring perceived organizational support. Respondents were asked to give their responses on a 7-point Likert scale. Higher score indicates weaker perceived organizational support for family responsibilities fulfillment. For the purpose of this study family-supportive organization perception variable was dichotomized on the basis of median score (belowmedian score indicated positive family-supportive organization perceptions; equal- or above-median score denoted negative family-supportive organization perceptions).

The authors reported strong psychometric characteristics and 1-dimensional structure. Internal consistency of the scale in this study was $\alpha=0.77$.

Salience with life roles was assessed by Life Role Salience Scales [8]. It contains 3 subscales with the total of 15 items scored on a 7-point Likert scale. Higher score denotes higher expressed attachment to/importance of parental, marital and occupational role. Namely, commitment to life roles as one of the aspects of its salience was measured in this research. Reliability of all 3 subscales as reported 
by the authors is above $\alpha=0.8$. Reliability coefficients obtained in this research were $\alpha=0.5$ for occupational role subscale and $\alpha=0.7$ for parental role subscale and marital role subscale, respectively.

Satisfaction With Life Scale (SWLS) [25] with 5 items was applied to measure global life satisfaction. Respondents gave their answers on a 7-point Likert scale where higher score indicated higher life satisfaction. As stated by the authors, SWLS had good psychometric properties, i.e., high internal consistency and high temporal reliability. Cronbach's $\alpha$ reliability of SWLS in this study was 0.7 .

The subscale of Oldenburg Burnout Inventory [27] with 8 items aimed to assess exhaustion was used for measuring this construct. Responses were given on a 7-point Likert scale with higher obtained scores indicating higher expressed exhaustion. The authors reported acceptable reliability (Cronbach's $\alpha$ ) of this subscale. Its internal consistency in this research was $\alpha=0.66$.

\section{Statistical data analysis}

Four hierarchical multiple linear regression analyses ( 2 among participants with positive family-supportive organizational perception and other 2 among participants with negative family-supportive organizational perception) were conducted in order to test proposed associations among study variables (only participants who answered all questions were included in the analyses; data for the variable length of marriage was missing). In the first block respondents' marriage duration and the number of children were entered as control variables. In the next 3 blocks, occupational role commitment, parental role commitment and marital role commitment, respectively, were entered as predictors of life satisfaction, i.e., exhaustion as criterion variables. In the Results section only the last model or Model 4 was presented because it contained all obtained data in the analysis, i.e., the data from the previous models, Model 1, Model 2 and Model 3. Moderator effect of family-supportive organization perception was tested using the test of differences in regression coefficients among models proposed by Clogg et al. [29].

\section{RESULTS}

In the Table 1 basic descriptive statistics of research variables are presented. As it could be seen, life satisfaction, parental and marital role commitment were relatively highly expressed if compared to the scale mean which was 4 (ranging from 1 to 7). Occupational role commitment and exhaustion were slightly above the scale mean of 4.

The hierarchical multiple linear regression analysis (Table 2) revealed that only occupational role commitment was a significant predictor of life satisfaction among

Table 1. Basic descriptive statistics of study variables among health care professionals $(\mathrm{N}=87)$, teachers $(\mathrm{N}=85)$ and bankers $(\mathrm{N}=26)$ in Macedonia, 2016

\begin{tabular}{lcl}
\hline \multicolumn{1}{c}{ Variable } & $\begin{array}{c}\text { Range } \\
(\text { min.-max })\end{array}$ & M \pm SD \\
\hline Commitment [pts] & & \\
$\quad$ parental role & $1.00-7.00$ & $4.68 \pm 1.42$ \\
$\quad$ marital role & $1.00-7.00$ & $4.63 \pm 1.08$ \\
$\quad$ occupational role & $2.00-6.60$ & $4.58 \pm 1.44$ \\
Exhaustion [pts] & $1.88-7.00$ & $4.21 \pm 1.03$ \\
Life satisfaction [pts] & $1.20-7.00$ & $4.72 \pm 1.08$ \\
\hline
\end{tabular}

Min. - minimal value; max - maximal value; $\mathrm{M}$ - mean; SD - standard deviation. 
Table 2. Hierarchical linear regression analysis among respondents with negative family-supportive organization perception $(\mathrm{N}=96)$ - criterion: life satisfaction

\begin{tabular}{lccccc}
\hline \multicolumn{1}{c}{ Model 4 } & $\mathrm{B}$ & $\mathrm{SE}$ & $\beta$ & $\mathrm{t}$ & $95 \%$ CI for B \\
\hline Constant & 3.558 & 0.739 & & $4.812^{* * *}$ & $2.086-5.029$ \\
Marriage duration & 0.014 & 0.010 & 0.171 & 1.420 & $-0.006-0.033$ \\
Number of children & -0.211 & 0.163 & -0.159 & -1.295 & $-0.536-0.113$ \\
Commitment & & & & & \\
$\quad$ parental role & -0.057 & 0.091 & -0.081 & -0.624 & $-0.238-0.124$ \\
$\quad$ marital role & 0.060 & 0.104 & 0.075 & 0.573 & $-0.148-0.267$ \\
$\quad$ occupational role & 0.320 & 0.124 & 0.282 & $2.573^{*}$ & $0.073-0.568$ \\
\hline
\end{tabular}

Model 4 - the last regression model in the analysis containing all study variables.

$\mathrm{B}$ - non-standardized regression coefficient; SE - standard error of $\mathrm{B} ; \beta$ - standardized regression coefficient; $\mathrm{t}$ - test of statistical significance of $\beta$ coefficient; $\mathrm{CI}$ - confidence interval.

*** Significant at $\mathrm{p}<0.001$.

* Significant at $\mathrm{p}<0.05$.

respondents who perceived family-supportiveness of the organization where they worked as weak, accounting for $7.2 \%$ in the variance of life satisfaction $(F(1,81)=6.62$, $\mathrm{p}<0.05)$. The results precisely showed that study participants who perceived an organization as less familysupportive, but prescribed greater importance to their occupational role, were more satisfied with life in general $(\beta=0.28, \mathrm{t}=2.57, \mathrm{p}<0.05)$.

As it can be seen from the Table 3, findings demonstrated that occupational role commitment was weaker, but was still a significant predictor of life satisfaction among respondents with positive perception of family supportiveness of the work environment $(\beta=0.20$, $\mathrm{t}=1.97, \mathrm{p}<0.05)$. Further, it was found that life satisfaction in this group of surveyed employees was significantly predicted by the number of children. Employees who had more children reported higher satisfaction with life $(\beta=0.24, t=2.07, p<0.05)$. The number of children explained $11.3 \%$ of the variance in life satisfaction $(\mathrm{F}(1,91)=11.94, \mathrm{p}<0.001)$. Occupational role commitment accounted for additional $3.5 \%$ in the variance of life satisfaction $(\mathrm{F}(1,89)=3.89, \mathrm{p}<0.05)$.

Table 3. Hierarchical linear regression analysis among respondents with positive family-supportive organization perception $(\mathrm{N}=102)$ - criterion: life satisfaction

\begin{tabular}{lccccc}
\hline \multicolumn{1}{c}{ Model 4 } & $\mathrm{B}$ & $\mathrm{SE}$ & $\beta$ & $\mathrm{t}$ & $95 \%$ CI for B \\
\hline Constant & 1.634 & 0.830 & & $1.969^{*}$ & $-0.015-3.284$ \\
Marriage duration & -0.010 & 0.014 & -0.083 & -0.730 & $-0.037-0.017$ \\
Number of children & 0.399 & 0.193 & 0.240 & 2.068 & $0.016-0.783$ \\
Commitment & & & & & \\
$\quad$ parental role & 0.154 & 0.114 & 0.197 & 1.349 & $-0.073-0.381$ \\
$\quad$ marital role & 0.099 & 0.108 & 0.133 & 0.915 & $-0.116-0.313$ \\
$\quad$ occupational role & 0.250 & 0.127 & 0.200 & $1.971^{*}$ & $-0.002-0.502$ \\
\hline
\end{tabular}

Abbreviations and explanations as in Table 2. 
Table 4. Hierarchical linear regression analysis among respondents with negative family-supportive organization perception $(\mathrm{N}=96)$ - criterion: exhaustion

\begin{tabular}{lccccc}
\hline \multicolumn{1}{c}{ Model 4 } & $\mathrm{B}$ & $\mathrm{SE}$ & $\beta$ & $\mathrm{t}$ & $95 \%$ CI for B \\
\hline Constant & 4.191 & 0.821 & & $5.104^{* * *}$ & $2.557-5.824$ \\
Marriage duration & 0.011 & 0.011 & 0.122 & 0.991 & $-0.011-0.032$ \\
Number of children & -0.297 & 0.181 & -0.204 & -1.640 & $-0.657-0.063$ \\
Commitment & & & & & \\
$\quad$ parental role & -0.187 & 0.101 & -0.244 & -1.849 & $-0.388-0.014$ \\
$\quad$ marital role & 0.261 & 0.116 & 0.300 & $2.261^{*}$ & $0.031-0.491$ \\
$\quad$ occupational role & 0.058 & 0.138 & 0.047 & 0.423 & $-0.216-0.333$ \\
\hline
\end{tabular}

Abbreviations and explanations as in Table 2.

Table 5. Hierarchical linear regression analysis among respondents with positive family-supportive organization perception $(\mathrm{N}=102)$ - criterion: exhaustion

\begin{tabular}{lccccc}
\hline \multicolumn{1}{c}{ Model 4 } & $\mathrm{B}$ & $\mathrm{SE}$ & $\beta$ & $\mathrm{t}$ & 95\% CI for B \\
\hline Constant & 3.297 & 0.728 & & $4.527^{* *}$ & $1.850-4.744$ \\
Marriage duration & 0.013 & 0.012 & 0.121 & 1.082 & $-0.011-0.037$ \\
Number of children & -0.220 & 0.169 & -0.149 & -1.297 & $-0.556-0.117$ \\
Commitment & & & & & \\
$\quad$ parental role & -0.138 & 0.100 & -0.200 & -1.384 & $-0.337-0.060$ \\
marital role & 0.324 & 0.095 & 0.494 & $3.432^{* *}$ & $0.137-0.512$ \\
$\quad$ occupational role & 0.090 & 0.111 & 0.081 & 0.808 & $-0.131-0.311$ \\
\hline
\end{tabular}

** Significant at $\mathrm{p}<0.01$.

Other abbreviations and explanations as in Table 2.

Performed analyses (Table 4 and 5) revealed that only attachment to marital role significantly and positively predicted exhaustion. More precisely, the association between marital role commitment and exhaustion was weaker among study participants who perceived the support from the working environment in regard to family life as weak $(\beta=0.30, \mathrm{t}=2.26, \mathrm{p}<0.05)$ accounting for $10.9 \%$ in the variance of the criterion $(\mathrm{F}(1,90)=12.24, \mathrm{p}<0.01)$. On the other hand, marital role commitment was evidently highly related to exhaustion among respondents who reported that such support was strong $(\beta=0.494, \mathrm{t}=3.43$, $\mathrm{p}<0.01$ ) explaining $6.2 \%$ of the variability in the exhaustion $(\mathrm{F}(1,82)=5.55, \mathrm{p}<0.05)$.
In summary, the explored relationship of occupational role commitment to life satisfaction and the observed association between marital role commitment and exhaustion were stronger among surveyed employees who reported positive family-supportive organization perception, but the tested moderation effect of this variable was not statistically significant $(Z=0.35, p>0.05$ and $Z=0.42, p>0.05$, respectively). Findings demonstrated that family-supportive organization perception moderated the relationship between the number of children and satisfaction with life, that is participants who perceived an organization as family-supportive and had more children were more satisfied with their life in general $(Z=2.35, p<0.05)$. 


\section{DISCUSSION}

In this study, the relationship of parental, marital and occupational role salience to subjective well-being at various levels of family-supportive organization perception among health care professionals (doctors and nurses), primary and secondary school teachers and bankers was explored. It was found that surveyed employees in health care, educational and financial sector expressed relatively high attachment to their parental and marital role and reported slightly lower commitment to occupational role. Considering that one of the aspects of achieved work-family balance is equal engagement in both work and family roles [2], it can be concluded that balance of life roles among participants in this study is at a quite acceptable level. In regard to subjective well-being, respondents reported they were moderately exhausted by exposed work demands and more than average satisfied with their life in general.

Results from applied hierarchical linear regression analyses revealed that study participants who perceived an organization as strongly supportive for their family issues and had more children, expressed higher degree of pleasure. Namely, in accordance to Ho et al.'s [21] explanation, it can be concluded that employees with positive family-supportive organization perception were more satisfied with their family and had opportunities to build high quality relations with their children. Accordingly, the number of children statistically significantly contributed to feeling of fulfillment and happiness, i.e., to life satisfaction in general. In that constellation, as it was found, only occupational role salience significantly predicted life satisfaction, but the relationship between these 2 variables was weaker in the mentioned group of respondents.

On the other hand, when employees perceived an organization as less family-supportive, the number of children did not predict satisfaction in life, while association of occupational role commitment with life satisfaction became stronger. Yet, results showed that family-supportive organization perception statistically significantly moderated only the link between the number of children and satisfaction with life in general, but not the link between occupational role commitment and satisfaction with life.

Despite how participants in this study perceived organization's philosophy to family life, probably greater commitment to work and experienced self-realization in profession spillover to other life domains. This is in line with the hypothesized reciprocal relationship life-job satisfaction [30]. In addition, this finding may be explained through the mechanism based on enrichment theory that positive experiences in one role improve quality of life in another life role [31] leading to greater life satisfaction.

As it has been cited by Greenhaus and Powel [10] when the role is more salient for the individual, then more time and emotion are invested in that role. Accordingly, the significant positive relationship between marital role commitment and exhaustion found in this study may be explained by substantial time engagement in both, marital and work obligations fulfillment concurrently [7]. In other words, considerable time invested in and more emotion attached to marital role lead to energy consumption, which in turn increases exhaustion based on high job demands as a condition that also needs energy. This is consistent with the reported positive link between psychological commitment to the role and role strain [9] and with the assumption of role theory that multiple life roles result in the inter-role conflict when individuals experience difficulty performing each role successfully because of conflicting demands [1]. The positive relationship between marital role commitment and emotional strain also derives from overextended job demands, which can be seen in the context of possible lack of family support, especially emotional support from the spouse as a more important factor in decreasing workfamily conflict and family-work conflict than perceived generic support, i.e., organizational and perceived supervisor support [32]. It should be mentioned that participants in this study, particularly teachers and health care professionals are overloaded by administrative job demands that 
are seen as time-conflicting with other more eminent job obligations such as work with students, i.e., patients. Given that life role salience should be considered within specific developmental and cultural context [33], these results may be interpreted through more dominant traditional values than egalitarian values in the Macedonian context.

In addition, it was revealed that moderating effect of perceived organizational support to family issues on the link between commitment to marital role and exhaustion was not significant. Similarly, empirical findings of Seiger and Wiese [16] favored social support from supervisor, coworkers and family as an antecedent of work-family conflict, but not as a moderator of the relationship of strain to work-family conflict.

\section{Limitations of the study and future directions}

This study has few limitations. Firstly, it is based on the cross-sectional design that does not permit to conclude that a causal relationship between investigated variables exists. Then, self-reported measures were used which might bring altered and biased responses. Additional limitations arise from demographic characteristics of the study participants: there were more women than men employed in 3 sectors (health care, education and financial).

Despite the limitations, the conducted research has contributed to the extension of existing work-family literature with new empirical findings from developing, non-western context. Further investigations of proposed relationships among variables in this study from the perspective of boundary management styles and work-family transition frequency [28] together with family support, in particular, emotional support from the family members [34] and accessibility to family supportive practices including study participants with different professions are needed.

In addition, gender and age differences in regard to mentioned variables should be explored in order to give more extensive base for organizational practices planning in the field of work-family balance and employees' psychological health.

\section{CONCLUSIONS}

Despite the limitations, this study has shown that surveyed employees' commitment to work and marital roles and their subjective well-being are significantly associated, but contrary to what has been assumed, this relationship is not moderated by perceived organizational support to family issues. More precisely, it has been revealed that stronger commitment to occupational role contributes to highly expressed life satisfaction, while exhaustion is predicted by marital role commitment. Further findings have demonstrated that family-supportive organization perception moderates the association of the number of children with life satisfaction, i.e., study participants who perceive an organization as family-supportive and have more children are more satisfied with their life in general. Results have highlighted the importance of work and family roles for subjective well-being as characteristics that may contribute to higher work engagement, success and family satisfaction. Accordingly, findings in this study can be used in development of practices aimed to strengthen occupational role commitment and fulfillment of family responsibilities as they are significant for better psychological health of the employees and consequently, for the organizational health.

\section{REFERENCES}

1. Greenhaus JH, Beutell NJ. Sources of conflict between work and family roles. Acad Manage Rev. 1985;10(1):76-88.

2. Greenhaus JH, Collins KM, Shaw JD. The relation between work-family balance and quality of life. J Vocat Behav. 2003;63(3):510-31, https://doi.org/10.1016/S0001-8791(02) 00042-8.

3. Hartman RI, Stoner CR, Arora R. An investigation of selected variables affecting telecommuting productivity and satisfaction. J Bus Psychol. 1991;6(2):207-25, https://doi. org/10.1007/BF01126709.

4. Allen TD, Cho E, Meier LL. Work-family boundary dynamics. Ann Rev Organ Psychol Organ Behav. 2014;1:99-121, https://doi.org/10.1146/annurev-orgpsych-031413-091330. 
5. Allen TD. The work-family role interface: A synthesis of the research from industrial and organizational psychology. In: Weiner IB, editor. Handbook of psychology. 2nd ed. John Wiley \& Sons, Inc.; 2013. p. 698-719. Available from: http:// onlinelibrary.wiley.com/book/10.1002/9781118133880.

6. Neville DD, Super DE. The Salinece Inventory: Theory, application and research. Palo Alto (CA): Consulting Psychologists Press; 1986.

7. O'Neil R, Greenberger E. Patterns of commitment to work and parenting: Implications for role strain. J Marriage Fam. 1994;56(1):101-12, https://doi.org/10.2307/352705.

8. Amatea ES, Gail Cross E, Clark JE, Bobby CL. Assessing the work and family role expectations of career-oriented men and women: The life role salience scales. J Marriage Fam. 1986;48(4):831-8, https://doi.org/10.2307/352576.

9. Perrone KM, Civiletto CL. The impact of life role salience on life satisfaction. J Employment Couns. 2004;41(3): 105-16, https://doi.org/10.1002/j.2161-1920.2004.tb00884.x.

10. Greenhaus JH, Powell GN. When work and family collide: Deciding between competing role demands. Organ Behav Hum Decis Process. 2003;90(2):291-303, https://doi. org/10.1016/S0749-5978(02)00519-8.

11. Kulik L, Shilo-Levin S, Liberman G. Multiple roles, role satisfaction, and sense of meaning in life: An extended examination of role enrichment theory. J Career Assess. 2015; 23(1):137-51, https://doi.org/10.1177/1069072714523243.

12. Allen TD. Family-supportive work environments: The role of organizational perceptions. J Vocat Behav. 2001;58(3): 414-35, https://doi.org/10.1006/jvbe.2000.1774.

13. Wayne HJ, Casper WJ, Matthews RA, Allen TD. Familysupportive organization perceptions and organizational commitment: The mediating role of work-family conflict and enrichment and partner attitudes. J Appl Psychol. 2013;98(4):606-22, https://doi.org/10.1037/a0032491.

14. Butts MM, Casper WJ, Yang TS. How important are work-family support policies? A meta-analytic investigation of their effects on employee outcomes. J Appl Psychol. 2013;98(1):1-25, https://doi.org/10.1037/a0030389.
15. Booth SM. Family supportive organization perceptions, work role overload, and burnout: Crossover effects of burnout on recovery [master's thesis]. Baton Rouge: Louisiana State University; 2011 [cited 2017 Mar 3]. Available from: http://digitalcommons.lsu.edu/gradschool_theses/3151.

16. Seiger CP, Wiese BS. Social support from work and family domains as an antecedent or moderator of work-family conflicts? J Vocat Behav. 2009;75(1):26-37, https://doi. org/10.1016/j.jvb.2009.03.001.

17. Terry DJ, Nielsen M, Perchard L. Effects of work stress on psychological well-being and job satisfaction: The stressbuffering role of social support. Aust J Psychol. 1993;45 (3):168-75, https://doi.org/10.1080/00049539308259135.

18. Wadsworth LL, Owens BP. The effects of social support on work-family enhancement and work-family conflict in the public sector. Publ Admin Rev. 2007;67(1):75-87, https://doi.org/10.1111/j.1540-6210.2006.00698.x.

19. Panaccio A, Vandenberghe C. Perceived organizational support, organizational commitment and psychological well-being: A longitudinal study. J Vocat Behav. 2009;75(2):224-36, https://doi.org/10.1016/j.jvb.2009. 06.002 .

20. Kossek EE, Pichler S, Bodner T, Hammer LB. Workplace social support and work-family conflict: A meta-analysis clarifying the influence of general and work-familyspecific supervisor and organizational support. Pers Psychol. 2011;64(2):289-313, https://doi.org/10.1111/j.17446570.2011.01211.x.

21. Ho MY, Chen X, Cheung FM, Liu H, Worthington EL. A dyadic model of the work-family interface: A study of dual-earner couples in China. J Occup Health Psychol. 2013;18(1):53-63, https://doi.org/10.1037/a0030885.

22. Andrews FM, Withey SB. Social indicators of well-being: America's perception of life quality. New York: PlenumPress; 1976, https://doi.org/10.1007/978-1-4684-2253-5.

23. Shin DC, Johnson DM. Avowed happiness as an overall assessment of the quality of life. Soc Indic Res. 1978;5 (1-4):475-92, https://doi.org/10.1007/BF00352944. 
24. Pavot W, Diener E. Review of the Satisfaction With Life Scale. Psychol Assess. 1993;5(2):164-72, https://doi.org/10. 1037/1040-3590.5.2.164.

25. Diener ED, Emmons RA, Laresen RJ, Griffin S. The Satisfaction With Life Scale. J Pers Assess. 1985;49(1):71-5, https://doi.org/10.1207/s15327752jpa4901_13.

26. Wright TA, Cropanzano R. Emotional exhaustion as a predictor of job performance and voluntary turnover. J Appl Psychol. 1998;83(3):486-93, https://doi.org/10.1037/0021-90 10.83.3.486.

27. Demerouti E, Mostert K, Bakker AB. Burnout and work engagement: A thorough investigation of the independency of both constructs. J Occup Health Psychol. 2010;15(3): 209-22, https://doi.org/10.1037/a0019408.

28. Booth SM, Matthews RA. Family-supportive organization perceptions: Validation of an abbreviated measure and theory extension. J Occup Health Psychol. 2012;17(1):41-51, https://doi.org/10.1037/a0026232.

29. Clogg CC, Petkova E, Haritou A. Statistical methods for comparing regression coefficients between models. Am J Sociol. 1995;100(5):1261-93, https://doi.org/10.1086/230638.
30. Schmitt N, Bedeian AG. A comparison of LISREL and twostage least squares analysis of a hypothesized life-job satisfaction reciprocal relationship. J Appl Psychol. 1982;67(6): 806-17, https://doi.org/10.1037/0021-9010.67.6.806.

31. Greenhaus JH, Powell GN. When work and family are allies: A theory of work-family enrichment. Acad Manage Rev. 2006;31(1):72-92, https://doi.org/10.5465/AMR.2006. 19379625.

32. Salvarajan TT, Cloninger PA, Sinhg B. Social support and work-family conflict: A test of an indirect effects model. J Vocat Behav. 2013;83(3):486-99, https://doi.org/10.1016/ j.jvb.2013.07.004.

33. Niles SG, Goodnough GE. Life-role salience and values: A review of recent research. Career Dev Q. 1996;45(1): 65-86, https://doi.org/10.1002/j.2161-0045.1996.tb00463.x.

34. Wayne JH, Randel AE, Stevens J. The role of identity and work-family support in work-family enrichment and its work-related consequences. J Vocat Behav. 2006;69(3): 445-61, https://doi.org/10.1016/j.jvb.2006.07.002.

This work is available in Open Access model and licensed under a Creative Commons Attribution-NonCommercial 3.0 Poland License - http://creativecommons.org/ licenses/by-nc/3.0/pl/deed.en. 